\title{
Online Journal of
}

Complementary \& Alternative Medicine

\section{Toxic World}

\author{
Viviana Siddhi* \\ Slovenian-Born Artist, NGO Mandala Transformation, USA
}

*Corresponding author: Viviana Siddhi, Slovenian-Born Artist with American

Citizenship, NGO Mandala Transformation, Inc., California, USA.

\section{Received Date: July 06, 2020}

Published Date: July 15, 2020

\section{Short Communication}

Toxic chemicals affect every aspect of our bodies - cells tissues, and organs become overloaded with waste. A human body has organs of elimination and detoxification to clear away the accumulation of these pollutants. But when our organs become overwhelmed with too much work, a built-up of toxicity occurs and we become more and more fatigued, mentally fogged, and vulnerable to sickness. We can choose good health habits that will strengthen and protect us. A strong, healthy body can resist toxic overload and disease, so there's great incentive to become stronger, healthier, and more resistant.

Chemicals that were designed to enhance our lives were introduced into our environment over fifty years ago, but in the past half century hundreds of them have been shown to be either highly toxic or at least troublesome and irritating to our complex biological system. It leaves us wondering what happened between what was supposed to make our lives better but instead is making us sick. Environmental toxins disrupt normal metabolic functioning of the body, which over time can lead to poor quality of life, and have been linked to conditions such as chronic fatigue syndrome, fibromyalgia, inflammatory diseases, autoimmune disorders, cancer, etc.

Modern agriculture and food-preservation methods have done serious damage to the human diet. Human body is exposed to acidic wastes from processed food and chemical additives. Those are common sources in all degenerative diseases. When acidic wastes accumulate, they cause organs to malfunction and break down. The book Acid-Alkaline Balance Diet explores new treatment in alternative medicine. We should know how to balance the body's acid-alkaline $\mathrm{pH}$ factor to improve health.

"When the body's acidic load becomes too large, some acid particles remain in the blood. They trigger the onset of cardiovascular disease by making scratches and bumps on the inside walls of arteries and veins. These injuries are "bandaged" over with cholesterol, triglycerides, calcium, and other wastes. Of course, the higher the cholesterol and triglyceride levels, the thicker the "bandage" and the narrower the arteries." [1]

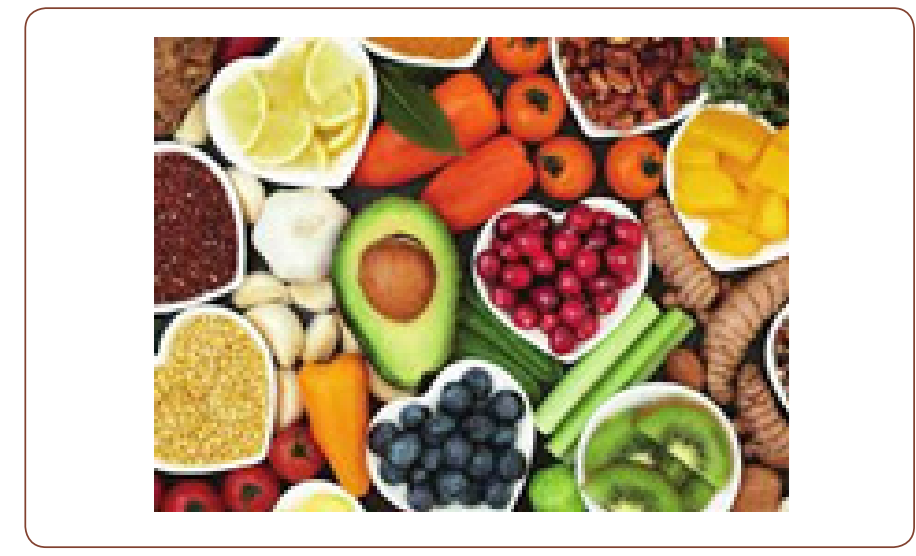

When it comes to water, we can use purified for drinking and food preparation to avoid the hidden sources of pollution. We can make healthy food choices each and every day. We can choose whole, unprocessed, organic foods grown without pesticides and chemical fertilizers.

The use of pharmaceutical drugs often causes side effects that are almost worse than the conditions they are designed to treat. We can get second opinions from doctors who specialize in natural 
medicine and search for nontoxic natural remedies whenever possible.

Once we've made some healthy changes, we should no longer crave the things that have been undermining our health and making us feel less vibrant and well.

The tissues and organs of our bodies do best if they are sustained at a more alkaline rather an acidic $\mathrm{pH}$ environment. The term " $\mathrm{pH}$ " refers to the level of acidity and alkalinity in the body.

"Biological systems like the human body must maintain a balance in the mid ranges of this pH scale - between 4.0 and 9.5." [2]

\section{Acid food:}

- $\quad$ Meats \& animal products

- $\quad$ Dairy products

- $\quad$ Fried foods

- Sugar

- $\quad$ Grains (bread and pasta)

- $\quad$ Most fruits

- $\quad$ Fast foods and junk food

- $\quad$ Coffee, tea, soda, alcohol

Alkaline food:

- $\quad$ Vegetables

- $\quad$ Vegetable juices

- Good oils (coconut and olive)

- $\quad$ Nuts and seeds

- $\quad$ Most legumes

- $\quad$ Alkaline water

- $\quad$ Some fruit

If most of the food we eat metabolizes into an alkaline ash, it nourishes and strengthens the body and gives us plenty of energy. On the other hand, if the majority of our food is metabolized into an acidic residue, that is toxic, it leads to stress on our organs and tissues, low energy, tiredness. Chemical and environmental pollutants, free radicals, and electromagnetic fields, as well as negative thoughts and emotions like fear, worry, anger, and anxiety are all toxic. If our cells, tissues, and organs are fed with acidic fluids, they can become inflamed, which can lead to disease. If the blood becomes too acidic or too basic, we feel sick.

Our organs and other tissues suffer from inflammation caused by the acidity and shortage of minerals to help neutralize it. An overly acidic body is also a toxic body. Microorganisms like bacteria, viruses, and yeast thrive in an acidic medium as do cancer cells, but they do not thrive in an alkaline environment.

Our bodies are over 70\% water, so we need to continually drink purified water to keep properly hydrated. Water is vital to health because it helps flush waste through the system.

"Water increases endurance and energy, aids digestion, regulates body temperature, and facilitates muscular and nervous system activity. Our bodies are designed to deliver essential nutrients, oxygen, hormones, and antibodies into our cells through an aqueous medium." [2]

\section{"Summary of Detoxing for Life}

Step 1: Eat whole, alkalizing, organic, non-GMO foods: remove as many sources of toxicity as possible: drink plenty of purified water and eat 50 to 75 percent of your food raw.

Step 2: Add fresh vegetable juices to your diet at least once or twice a day.

Step 3: Complete a one- to three-day juice fast.

Step 4: Complete the colon, liver and gallbladder; and/or kidney Cleanse programs." [2]

Most people neglect personal healthcare and wellness. Even less consider the importance of cellular health and the importance of supplying your cellular body all the oxygen and vital nutrients they need in both to a total and balanced level.

As your pursuit of true physical wellness in a harmony with your cellular-self and a fully complete and balanced manner, do not forget of the balance of your whole life.

Faults, lies, accusations, in us, the people, for not expressing more gratitude and support for those who do focus on health care as their priority, are bringing a lot of toxic elements in our lives. Fault mostly lies in each of us for neglecting and abusing our own bodies on the first place and secondary others. We know we should have eaten better and taken better care of ourselves. Fault lies also in acceptance of "it's too late" in the face of serious medical illness. Yet with all this said, assigning fault was never a cure rather a source of illness.

"A sucker is born every minute."

$90 \%$ of water, over half of the human body and only approximately $20 \%$ of the air we breathe is oxygen. Oxygen helps to remove wastes from the human body. It purifies and sterilizes the body as powerful defense against pathogens. Without oxygen, our bodies and pour cells quickly die. In a medical emergency, the most common immediately help is to administer oxygen. Having 
a sufficient supply of oxygen to our cells is absolutely critical. In the right concentration, oxygen maximizes the healing process, the immune system and disease prevent ion. Every cellular, organ and body function require oxygen, which is carried through the human body by blood. We can live without food for days, (weeks). We can live without water for several days; however, we die right the way if we do not have enough oxygen.

"Hydrogen peroxide is created in nature by lightening. During an electrical storm the air will come to have a crisp, fresh and clean smell to it. It is not just that the air is electrically charged, it also has increasing trace amounts of hydrogen peroxide that sterilizes the air and increases the oxygen level in the air.

Pure hydrogen peroxide will exist only briefly in nature. Hydrogen peroxide action is why the air seems fresh. The air has been purified by the lightening and the hydrogen peroxide, which also eliminated many bacteria, fungus and viruses in the air. The air will smell sweet, clean, somewhat damp and a bit heavy, although in an attractive way." [3]

"Deprive a cell $35 \%$ of its oxygen for 48 hours and it will become cancerous." - Nobel Prize winner Otto Warburg.

"A healer who claims to cure cancer with a 42-day fast of natural juices and herbal teas - outrageous?" - Jane Heimlich

Fasting has long been used both as a preventive measure and as a cure, particularly for degenerative conditions, and to purge the body of impurities or toxins. Knowledgeable in this tradition, Rudolf Breuss, a naturopathic practitioner, developed a 420day juice fasting program to nourish the body but starve cancer.

\section{"My Juice Mixture:}

To prepare the juice, take $3 / 5$ beets, $1 / 5$ carrots, $1 / 5$ celeriac, and then add a little black radish and one egg-sized potato. For example:

$$
\begin{aligned}
& 300 \mathrm{~g} \text { (9.6 oz.) beet root } \\
& 100 \mathrm{~g} \text { ( } 3.2 \mathrm{oz} .) \text { carrots }
\end{aligned}
$$

$100 \mathrm{~g}(3.2 \mathrm{oz})$ celeriac (celery root)'30 g (1.06 oz.) black radish juice

1 potato, the size of an egg" [4]

Drink juice slowly.

Ayurveda teaches that each individual has the power to heal himself. Thus, this science of life offers everyone the freedom to recover health by understanding the body and its needs. Every human being has ability to remain healthy maintenance and a stable healthy routine. Also important are pursuit of traditional practices such as yoga and breathing exercises; and an understanding of the spiritual practices that can create harmony and happiness. "There are certain foods that are incompatible when eaten together, such as fish and milk, meat and milk, yogurt and beef, and sour fruits and milk. In addition, most melons should be eaten alone. In combination with other foods, they create clogging and may prevent absorption by the intestines. These effects could cause an imbalance in the tridosha. Toxins result when these incompatible foods are ingested together." [5]

Fasting, promotes self-healing by casting off poisons. It is not so much a cure as it is an opportunity for rejuvenation. The principal of fasting is straightforward: health restored through cleansing. Our bodies have a limited capacity to store and/or eliminate nondigestible matter. These materials, if left to circulate through the body system, are antagonists to cells and organs and are collectively described as toxins. As this toxic load accumulates from years of bad diet, air/water pollution, etc, it begins to interfere with normal functioning and our elimination becomes impaired. "Natural hygienists theorize that this toxemia is the cause of "disease". [6]

Being conscious about our food choices is an act of self-care and a choice of self-love. Without self-love in place, little can truly flourish in our lives. Choosing to care for our bodies can be the first step back to wholeness, harmony and healthy living. Disease is actually caused by an accumulation of toxins in the body. There are foods that can help to detoxify the body.

Gelatinous plant food fibers from chia seeds, seaweed, flax and aloe vera absorb and bind with toxins as they move through the digestive system. Cilantro binds with heavy metals and moves them through your system, so they don't bind with your cells, and parsley is a great blood cleanser.

\section{"Holy and Healing Water}

Natural, living spring water is a natural remedy. But don't drink water just to become healthier. Drink water for its consciousnessexpanding purposes as well. Water is consciousness! It is not a coincidence that our brain is ninety percent water. Water is full of living energy and healing information because it gives the body's innate self-healing forces the energy it needs to regenerate and recharge its batteries." [7]

\section{Acknowledgement}

None.

\section{Conflict of Interest}

Author declare no conflict of interest.

\section{References}

1. Felicia Drury Kliment (2002) The Acid Alkaline Balance Diet Professional Publishing McGraw-Hill, New York, p.4.

2. Cherie Calbom, John Calbom (2008) Juicing, Fasting, And Detoxing for Life. Grand Central Publishing, New York, p.22, p.28, p.129.

3. Mary Wright (2014) The Power of Hydrogen Peroxide Miracle Path to Wellness, USA, p.49. 
4. Rudolf Breuss (1995) The Breuss Cancer Cure. Books Alive, Canada, p.29.

5. Vasant Lad (1990) Ayurveda, The Science of Self-Healing. Lotus Press, Twin Lakes, WI, p.81.
6. Steve Meyerowitz (1996) Juice Fasting \& Detoxification Sproutman Publications, Great Barrington, MA, p.3.

7. Barbara Hendel, Peter Ferreira (2002) Water \& Salt, The Essence of Life. Institute for Profound Living, USA, p.64. 